\title{
Rede de proteção aos idosos do Rio de Janeiro: um direito a ser conquistado
}

\author{
The net for protection to the elderly of Rio de Janeiro: \\ a right to be conquered
}

Edinilsa Ramos de Souza ${ }^{1}$

Adalgisa Peixoto Ribeiro ${ }^{1}$

Soraya Atie ${ }^{2}$

Amaro Crispim deSouza ${ }^{1}$

Christiane da Cunha $\mathrm{M}_{\text {arques }}{ }^{3}$

${ }^{1}$ Centro Latino Americano de Estudos deViolência eSaúde - CLAVES, Escola Nacional deSaúde Pública, Fiocruz. Avenida Brasil 4036/700, M anguinhos. 21040-361 Rio deJaneiro RJ. edinilsa@claves.fiocruz.br ${ }^{2}$ Bolsista de Apoio Técnico daFundação do Amparo à Pesquisa do Estado do Rio deJaneiro - FAPERJ.

${ }^{3}$ Bolsista de Iniciação

Científica da Fundação do Amparo à Pesquisa do Estado do Rio de Janeiro FAPERJ.
Abstract This article is based on previous studies using triangulation of methods for investigating if violence is obstructing the rights of the elderly. A questionnaire with open and closed questions was applied to a convenience sample of 72 elderly ( 60 or more years of age) of both sexes. Twenty-two key-informants (elderly people, community leaders and representatives of public institutions) were interviewed. In this survey we investigate the net for protection to the elderly of the city of Rio de Janeiro (institutions, assistance flow, integration, denunciations and measures taken). We analyzed 763 records of occurrences of the Police Department for the A ged and 135 of the NEAPI (Nucleus for Special Assistance for the Aged), taken care of in 2004. We emphasize domestic violence committed by close relatives and point to the need of structuring the formal net through increasing the number of institutions for protection to the aged, professional qualification, communication and integration among the agenciescomposing the net. We also consider important stimulating the informal nets for support and protection to the elderly. Key words Violence, Elderly, Net of protection, Rights of the elderly
Resumo Partimos de pesquisa anterior que triangulou métodos ao investigar se a violência impede a garantia dos direitos dos idosos. A uma amostra de conveniência de 72 idosos ( 60 ou mais anos), de ambos os sexos, aplicamos um questionário com questões abertas e fechadas e entrevistamos 22 informantes-chave (idosos, líderes comunitários e representantes de órgãos públicos). N este recorte, investigamos a rede de proteção ao idoso do município do Rio de Janeiro (instituições, fluxo do atendimento, articulação, denúncias que chegam e medidas tomadas). Analisamos 763 registros de ocorrências da Del egacia do I doso e135 do N EAPI, atendidas em 2004. D estacamosa violência doméstica perpetrada por parentes próximos. A pontamos a necessidade de estruturação da rede formal com aumento do número de instituições de proteção ao idoso, capacitação profisssional, comunicação earticulação entreosórgãos que a compõem. Julgamos importante estimular as redes informais de apoio e proteção aos idosos. Palavras-chave Violência, Idosos, Redes de proteção, Direitos do idoso 
Introdução

A população idosa foi a quemais cresceu no Brasil nos últimos quarenta anos, como resultado da queda da fecundidade e da mortalidade ${ }^{1}$. 0 fenômeno do envelhecimento émundial etraz à tona discussões acerca dos direitos dos idosos. No Brasil, esses direitos são garantidos pela Constituição de 1988, pela Política Nacional do Idoso de 1994, pelo Estatuto do Idoso, de 2003 e, no setor saúde, pela Política Nacional de Saúde do Idoso de 1999, atualizada em 2006. As diretrizes preconizadas nesse arcabouço legal são efetivadas pelas redes sociais que fornecem apoio e proteção aos idosos. É importante ressaltar que, embora os idosos estejam amparados legalmente, a violência que os atingeé a negação dos direitos de cidadania conquistados por eles, conforme mostram os dados apresentados no presente artigo. A violência contra o idoso éaqui entendida como todo maltrato que pode se expressar sob a forma de abuso físico, psicológico e sexual, abandono, negligência, abusos financeiros e autonegligência?2.

No caso específico do Estatuto do Idoso, os direitos individuais, políticos, civis, sociais eeconômicos dos idosos brasileiros são reconhecidos, além deste ser um instrumento demobilização de governo e sociedade em busca da garantia de acesso a uma rede deserviços de proteção contemplada nas diversas políticas brasileiras: assistência social, saúde, transporte, justiça, educação, cultura, trabalho e previdência.

Portanto, os conceitos de rede social, apoio social e rede de apoio social são centrais na fundamentação do presente artigo.

Segundo Sluski ${ }^{3}$, rede social étudo aquilo com que 0 sujeito interage, tudo que faz parte da rede relacional do indivíduo. Os relacionamentoscom a família e os amigos pressupõem troca de afeição, têm associações com o bem-estar subjetivo e estão presentes nas redes sociais ${ }^{4}$. Tanto 0 grupo familiar como a comunidade (amigos evizinhos) são lugares naturais de proteção e inclusão social onde as pessoas encontram companhia, a possibilidade de compartilhar confidências, prover serviços ou auxílio em atividades cotidianas ${ }^{5}$.

0 apoio social (social support) équalquer informação e/ou auxílio material, oferecidos por grupos e/ ou pessoas, com os quais se têm contatos sistemáticos e que resultam em efeitos emocionais e/ou comportamentos positivos. São trocas mútuas nas quais tanto aquele que recebe quanto 0 que oferece 0 apoio são beneficiados por darem um maior sentido a suas vidas.
Estudiosos do apoio social apontam para o seu papel na prevenção contra doenças, manutenção e recuperação da saúde ${ }^{6}$. 0 apoio social contribui criando uma sensação de coerência e controle da vida, afetan do ben eficamente o estado de saúde das pessoas?

O conceito derededeapoio social está vinculado às relações de troca, que implicam obrigações recíprocas e laços de dependência mútua. Este conceito possui, como idéia comum, a imagem de pontos conectados por fios, de modo a formar uma teia.

As redes de apoio social ao idoso podem ser: a) formais - políticas públicas direcionadas à população idosa em geral, agregando serviços de atenção à saúde, instituições jurídicas de garantia dos direitos, órgãos da previdência social, dentre outros e b) informais - relações marcadas pela"espontaneidadee reci procidade" 8 queauxiliam o idoso a manter os vínculos e proporcionam bem-estar. Considera-se como rede informal a família, a comunidade, os amigos e os vizinhos. Todas essas relações que ocorrem na vida social do idoso contribuem para a proteção e 0 apoio na garantia dos direitos previstos por lei.

0 objetivo do presenteartigo éanalisar arede de proteção aos idosos existente no município do Rio deJ aneiro, buscando visualizar que instituições fazem parte dessa rede, qual o fluxo do atendimento, como se dá a articulação, que tipos de denúncias chegam a esses órgãos e que medidas são tomadas no sentido de proteger os direitos do idoso.

\section{M etodologia}

Este trabal ho é parte de uma pesquisa realizada no Centro Latino Americano de Estudos sobre Violência eSaúde/CLAVES' ${ }^{9}$ no ano de2005, com o objetivo de investigar em que medida a violência impede a garantia dos direitos dos idosos. A pesquisa original envolveu metodologia quantitativa com aplicação de um questionário com questões fechadas e abertas, aplicado a uma amostra de conveniência de 72 pessoas de 60 ou mais anos, deambos os sexos, residentes nas doze comunidades que constituem uma área de baixa renda do município do Rio de Janeiro, na qual a pesquisa foi realizada. A capacidade funcional cognitiva e mental preservada foi outro critério para a inclusão dos idosos.

Foram também realizadas 22 entrevistas semiestruturadas: treze com idosos, seis com representantes da rede de apoio formal (um religioso, 
três representantes de associação de moradores da área e dois membros de órgãos de proteção externos à comunidade) e três da rede informal da comunidade (moradores antigos e líderes comunitários). A identificação inicial desses informantes-chave partiu do conhecimento prévio de um estudo realizado anteriormente ${ }^{10}$. Posteriormente, foi usada a técnica de bola de neve.

0 presente artigo aborda os dados relativos ao atendimento realizado no ano de 2004, por duas das principais instituições que atuam na proteção dos direitos dos idosos: a Delegacia do Idoso, que pertence à Secretaria de Segurança Pública do Rio de Janeiro, eo Núcleo Especial de Atendimento à Pessoa I dosa/NEAPI, quefaz parte da D efensoria Pública.

Para a coleta das informações, foi construído e pré-testado um questionário com questões fechadas e abertas, que foram posteriormente categorizadas, versando sobre: 1) caracterização da denúncia - evento gerador da denúncia; data do fato e da sua comunicação e quem foi o denunciante; 2) caracterização do fato e da vítima local deocorrência do evento; número de vítimas envolvidas; sexo, idade, cor, escolaridade e bairro de residência da vítima; 3 ) caracterização do autor - quanto ao sexo, idade, vínculo com a vítima, bairro de residência eseresideno mesmo endereço da vítima; 4) dinâmica do evento emedidas cautelares - qual foi o encaminhamento dado à denúncia.

Esses dados são aqui complementados com as percepções dos informantes sobre as denúncias que chegam às suas instituições, o fluxo do atendimento que realizam, as articulações com outros órgãos e as medidas adotadas. Também são trazidas as visões dos idosos sobre algumas dessas questões.

As informações foram processadas utilizando o software M icrosoft Access. U ma análise crítica dos dados foi feita e posteriormente, os dados foram exportados e manuseados para os softwares M icrosoft Excel e SPSS (Statistical Package for the Social Sciences), versão 13.0, em quese realizou a descrição defreqüências simples e relativas. As entrevistas foram analisadas com base na Análise de Conteúdo, modalidade temática, conforme preconiza M inayo ${ }^{11}$.

A pesquisa foi aprovada pelo Comitêde Ética em Pesquisa da Escola Nacional de Saúde Públi$\mathrm{ca/Fiocruz} \mathrm{etodos} \mathrm{os} \mathrm{participantes} \mathrm{assinaram} \mathrm{um}$ termo de consentimento livree esclarecido como orienta a Resolução n 196/96 do Conselho Nacional deSaúde.

\section{Resultados ediscussão}

\author{
Estruturação \\ da rede de proteção ao idoso
}

O Quadro 1 apresenta de forma sintética os principais organismos que atuam na proteção aos direitos do idoso do Rio de Janeiro. Essas instituições pertencem às esferasfederal, estadual e municipal e, embora prestem atendimento à população do estado, estão situadas na cidade do Rio de Janeiro.

Além das instituições mencionadas no Quadro 1 , existem outras que participam do sistema de proteção ao idoso. Esse é o caso de algumas organizações não governamentais e secretarias da esfera estadual e municipal, como por exemplo, a Gerência de Programas de Saúde do I doso da Secretaria M unicipal de Saúde que atua com projetos de desospitalização, capacitação de profissionais e treinamento de cuidadores.

A rede informal de apoio ao idoso éformada pelos familiares que, muitas vezes, em suas mais diversas gerações, convivem na mesma casa ou em espaços muito próximos à residência do idoso. Essa rede também inclui a família estendida, em que os familiares residem em casas separadas ou muito distantes, o que não significa 0 rompimento de relações, e a família modificada, na qual além dos integrantes do núcleo familiar incluem-se amigos íntimos e vizinhos ${ }^{5}$.

Além da família, os idosos da presente pesquisa contam com os amigos e conhecidos residentes na área, as lideranças comunitárias, os grupos de idosos e até mesmo os narcotraficantes. Esses últimos foram citados pelos idosos como fonte de solução de problemas vividos em seu cotidiano na comunidade, podendo ser considerados como membros da rede informal do idoso. Isso fica claro na fala deum líder informal entrevistado:

"Geralmente, eles procuram mais os bandidos para resolver alguma coisa, então acaba resolvendo tudo ali, ou dando-se um jeito empurrando com a barriga".

No sentido de incentivar o protagonismo dos moradores da comunidade aqui pesquisada, na luta pela diminuição da violência ea revitalização da área através da criação de espaços delazer ede projetos sociais, foi desenvolvido o movimento denominado Agenda Redutora de Violência. Amparada pela Fundação Oswaldo Cruz, essa iniciativa tem enfrentado muitos obstáculos e suas ações reprimidas pel os narcotraficantes que exercem suas atividades no local. 
Quadro 1. Principais instituições de proteção ao idoso do Rio de Janeiro.

\begin{tabular}{|c|c|}
\hline Instituição & Função \\
\hline Ministério Público/M P & $\begin{array}{l}\text { Recebe denúncias e fiscaliza o processo denúncia feito pelo idoso ou por órgãos } \\
\text { competentes, podendo encaminhar para os organismos de defesa }\end{array}$ \\
\hline $\begin{array}{l}\text { Promotoria de Justiça } \\
\text { de Proteção ao I doso } \\
\text { e à Pessoa Portadora de } \\
\text { Deficiência - PRODIDE }\end{array}$ & $\begin{array}{l}\text { Garante os direitos fundamentais assegurados no Estatuto, aplicando as medidas de } \\
\text { proteção previstas na lei, propondo e acompanhando as ações judiciais cabíveis e } \\
\text { atuando como fiscal da lei nas ações propostas por outros órgãos legitimados. } \\
\text { Geralmente recebe denúncias da Ouvidoria do M inistério Público ou do próprio } \\
\text { idoso }\end{array}$ \\
\hline $\begin{array}{l}\text { Vara da Infância, } \\
\text { Adolescência e I doso }\end{array}$ & $\begin{array}{l}\text { Fiscaliza, orienta e apura irregularidades de instituições, organizações governamentais } \\
\text { e não governamentais, abrigos e instituições de atendimento e congêneres que lidam } \\
\text { com o idoso, garantindo as medidas de proteção e atendimento primário previstas } \\
\text { na Lei }\end{array}$ \\
\hline $\begin{array}{l}\text { Defensoria Pública } \\
\text { Geral do Estado } \\
\text { do Rio de Janeiro }\end{array}$ & $\begin{array}{l}\text { Presta atendimento especializado por meio do Núcleo Especializado de } \\
\text { Atendimento à Criança, ao Adolescente e ao Idoso e busca atendimento prioritário } \\
\text { para o idoso em outros órgãos de atuação. Ú nica Instituição com representação } \\
\text { permanente no Conselho Estadual de Defesa dos Direitos da Pessoa Idosa }\end{array}$ \\
\hline $\begin{array}{l}\text { Núcleo Especial de } \\
\text { Atendimento à Pessoa } \\
\text { Idosa/NEAPI }\end{array}$ & $\begin{array}{l}\text { Criado no âmbito da Defensoria Pública Geral do Estado. Presta assistência jurídica } \\
\text { e gratuita; recebe denúncias de desrespeito e promove as medidas cabíveis para a } \\
\text { defesa dos direitos dos idosos. Encaminha para atendimento prioritário, aos Ó rgãos } \\
\text { da Defensoria Pública que prestam assistência jurídica ou a outros Órgãos Públicos } \\
\text { ou Privados }\end{array}$ \\
\hline Disque Denúncia & $\begin{array}{l}\text { Central comunitária de atendimento telefônico destinada a receber informações da } \\
\text { população sobre atividades criminosas e a transmiti-las aos órgãos de segurança } \\
\text { pública. Serviço da Secretaria de Segurança Pública do Estado do Rio de Janeiro que } \\
\text { vem ajudando as autoridades a combater o crime }\end{array}$ \\
\hline Ligue Idoso & $\begin{array}{l}\text { Espécie de ouvidoria da Secretaria de Ação Social do Estado. Fornece orientações } \\
\text { sobre os direitos dos idosos. Anonimamente ou não, recebe denúncias e reclamações } \\
\text { de quaisquer formas de violência a esse grupo. Encaminha os casos ao M inistério } \\
\text { Público, Conselho do I doso, Delegacia da Terceira Idade, Secretarias de Estado, de } \\
\text { Transportes e de Saúde, Associação dos Aposentados da Previdência Social do Rio } \\
\text { de Janeiro, Defensoria Pública, entre outros }\end{array}$ \\
\hline SOS Idoso & $\begin{array}{l}\text { Vinculado à Secretaria de Estado da Família e da Assistência Social - SEFAS. Presta } \\
\text { serviço ouvindo, orientando e esclarecendo acerca dos direitos sociais contribuindo } \\
\text { para a prevenção de violência. Recebe anonimamente ou não as denúncias e } \\
\text { reclamações de quaisquer formas de violência ao idoso. Encaminha denúncias às } \\
\text { instituições competentes após avaliação de uma equipe multidisciplinar e serve } \\
\text { como instrumento de estudo e pesquisa para elaboração de políticas públicas } \\
\text { voltadas para melhoria da qualidade de vida }\end{array}$ \\
\hline $\begin{array}{l}\text { Delegacia Especial de } \\
\text { Atendimento às Pessoas } \\
\text { de Terceira Idade ou } \\
\text { Delegacia do Idoso/DI }\end{array}$ & $\begin{array}{l}\text { Recebe denúncias, promove investigações e encaminha ao M inistério Público suas } \\
\text { conclusões, atendendo exclusivamente aos cidadãos de } 60 \text { ou mais anos. Busca } \\
\text { prestar atendimento especializado e diferenciado, podendo trabalhar com mais } \\
\text { tempo na denúncia-crime }\end{array}$ \\
\hline $\begin{array}{l}\text { Programa Estadual de } \\
\text { Orientação e Proteção ao } \\
\text { Consumidor/PROCON }\end{array}$ & $\begin{array}{l}\text { Recebe denúncias, fornece informações, orienta e conscientiza o consumidor, } \\
\text { mediando soluções entre fornecedores e consumidores }\end{array}$ \\
\hline $\begin{array}{l}\text { Secretaria Especial } \\
\text { da Terceira Idade }\end{array}$ & $\begin{array}{l}\text { Gera políticas para a população idosa do município. Elabora e implanta projetos. } \\
\text { Desenvolve programas de valorização do idoso, buscando parcerias. Elabora ações } \\
\text { concretas nas áreas social, cultural, esporte, saúde e lazer, objetivando integrar os } \\
\text { idosos em todos os âmbitos da sociedade, melhorando sua auto-estima }\end{array}$ \\
\hline
\end{tabular}




\section{Fluxo das denúncias}

As instituições acima citadas não funcionam como uma rede articulada eintegrada. Cadauma delas exerce suas funções de modo separado. A pesar disso, podemos identificar que existe um fluxo mínimo de atendimento às denúncias que envolvem pessoas idosas.

A denúncia criminal feita ao Ligue Idoso ou ao SOS Idoso é encaminhada aos Órgãos de Defesa (NEAPI, Promotoria da Terceira Idade, a Vara da Infância, Adolescente el doso e a D el egacia do Idoso). Esses órgãos de defesa recebem e registram os casos, tomam as providências e encaminham aqueles que não são de sua alçada para os órgãos competentes. Assim, por exemplo, uma denúncia criminal quechega ao NEAPI éencaminhada para uma Delegacia Legal, do Idoso ou a mais próxima da residência do idoso. Do mesmo modo, a denúncia criminal que chega ao Ligue Idoso ou ao SOS Idoso é encaminhada à delegacia que poderá acompanhar o andamento do processo, inclusive em outras delegacias.

Quando o idoso se dirige diretamente à dele gacia mais próxima de sua residência, sem ter passado pelo Liguel doso eSOSI doso, a unidade que recebe a denúncia não necessariamentenotifica à D elegacia do I doso. Assim, essa última não é a única que recebe as denúncias e, portanto, não tem conhecimento de todos os crimes contra o idoso, embora seja um dos órgãos principais de captação dos casos de desrespeito a seus direitos.

A Delegacia do Idoso, além de investigar e solucionar os casos, exerce papel de órgão informativo, sobretudo em relação ao SOS Idoso e Ligue Idoso para esclarecimentos sobre a natureza da denúncia (criminal ou cível). A orientação éde quea denúncia criminal seja encaminhada para a delegacia mais próxima da residência da vítima, uma vez que existe apenas uma delegacia especial izada para o atendimento a essegrupo populacional em todo o Estado do Rio de Janeiro.

A delegacia abre o inquérito eo encaminha à promotoria, que o devolve quando necessita de algum esclarecimento, sendo posteriormenteencaminhado ao juiz criminal. Segundo informação do representante da delegacia, em alguns países, como os Estados Unidos, não existe mais 0 inquérito policial. Ao se constatar, através de investigação, quem cometeu o ilícito penal, esteé encaminhado diretamente à J ustiça.

As denúncias cíveis quechegam ao Liguel doso, ao SOS I doso e às delegacias também podem ser registradas e encaminhadas aos órgãos de defesa ou a alguma outra instituição que a especificidade do caso requeira.

O NEAPI e a PRODIDE são os principais órgãos captadores das denúncias cíveis envolvendo idosos. Os casos que neles chegam são triados e, quando não são de sua competência, são encaminhados para outras instituições. Q uando se trata de situações que requerem orientação e garantia de assistência jurídica, eles prestam esse atendimento ou as encaminham para outra instituição de defesa que possa realizá-lo.

A ausência de um fluxo préestabelecido gera a duplicidade dedenúncias, poisum mesmo fato pode ser registrado em mais de uma instituição. Essa duplicidade só é solucionada ao chegar em juízo, passando-se a considerar apenas a denúncia mais antiga e incorporando no processo todas as demais. Ou seja, realizando a "juntada" solicitada pelo promotor.

Por sua vez, a rede informal dos idosos pesquisados se mostrou frágil, constituída por poucos membros, alguns deles com atuação muito restrita e cerceada pelo medo de represálias por parte dos grupos de narcotraficantes da área. Para muitos idosos, a família é o principal constituinte de sua rede de suporte social devido ao empobrecimento da rede de apoio formal oferecido pela comunidade e pelo Estado. A tarefa de amparar os idosos está quase que exclusivamente sob a responsabilidade das famílias, já que a organização comunitária também semostra bastanteincipiente ${ }^{12}$.

A pesar de, às vezes, ser o único constituinte dessa rede informal para o idoso, a família, idealizada como uma instituição protetora, não assume para si esse papel. 0 fato de grande percentual de autores de violência contra o idoso serem familiares, como veremos adiante, é mais um fator que leva à fragilidade dos laços afetivos.

Os líderes informais revelam que é difícil a articulação entre as iniciativas da comunidade, que estão desestimuladas por fracassos anteriores, e ainda declaram que só agem quando percebem que estarão seguros e sem nenhum risco de repercussões negativas para si próprios, mostrando claramente o medo que envolve esses moradores da comunidade.

\section{Caracterização do atendimento na Delegacia do I doso e no NEAPI}

Foram coletadas as informações de 898 registros provenientes do atendimento realizado no ano 
de 2004, sendo 763 na Delegacia do Idoso e 135 no NEAPI.

Antes da apresentação dos dados, é importante frisar que o total observado em algumas tabelas não corresponde ao total de registros, porque em um único registro pode haver mais de uma vítima, mais de um agressor ou mais de um motivo que levou à denúncia.

$\mathrm{Na}$ Tabela 1, observamos que os motivos mais freqüentes de denúncias na Delegacia do Idoso são os maus tratos (48,5\%), o constrangimento ilegal (11,1\%), a apropriação indébita $(10 \%)$ e a ameaça $(9,4 \%)$. No NEAPI, os maus tratos $(47,4 \%)$ e a apropriação indébita (24,0\%) também constituem as principais queixas dos idosos. N este último órgão surge, no entanto, 0 abandono como um importante motivo de de núncia em $21 \%$ dos registros realizados no ano de2004.

Os dados da Delegacia do Idoso, aqui apre sentados, são diferentes dos observados em delegacias de outros estados. Um levantamento re alizado na D el egacia de Proteção ao I doso de São Paulo, entre os anos de 1991 a 1998, constou que
13\% das denúncias são de agressão física e 60\%, de abusos financeiros ou de negligência familiar. Em Belo H orizonte, entre os anos de 1998 a 2001, cerca de $40 \%$ das queixas são de ameaça e perturbação da tranqüilidade ${ }^{13}$. Estes dados apontam para uma regionalização da violência que se mostra marcada pelas influências culturais do meio onde o idoso está inserido.

É importante ressaltar que, em $85,5 \%$ das ocorrências registradas na Delegacia do I doso e em $88,1 \%$ das denúncias do NEAPI, o fato ocorreu na resi dência da vítima, indicando quea violência doméstica é a principal forma de desrespeito ao idoso. A maioria dos fatos denunciados envolveu apenas uma vítima ( $74,3 \%$ na D elegacia e $71,1 \%$ no NEAPI).

Não foi encontrada nenhuma denúncia de moradores da área onde se desenvolveu o estudo. Este dado precisa ser complexificado, pois segundo depoimentos deagentes dasinstituições pesquisadas, as pessoas que residem em áreas de favelas muitas vezes não realizam a queixa por medo da ida da polícia à comunidade para investigação da denúncia. “Acho que violência maior

Tabela 1. Distribuição das denúncias realizadas na Delegacia do Idoso e no NEAPI no ano de 2004, segundo os motivos.

\begin{tabular}{|c|c|c|c|c|}
\hline \multirow[t]{2}{*}{ Motivos das denúncias } & \multicolumn{2}{|c|}{ Delegacia do idoso } & \multicolumn{2}{|c|}{ NEAPI } \\
\hline & $\mathrm{N}$ & $\%$ & $\mathrm{~N}$ & $\%$ \\
\hline Abandono & 30 & 3,4 & 48 & 21,0 \\
\hline Ameaça & 83 & 9,4 & 1 & 0,4 \\
\hline Apropriação Indébita & 88 & 10,0 & 55 & 24,0 \\
\hline Coação de atos civis & 3 & 0,3 & 1 & 0,4 \\
\hline Constrangimento Ilegal & 97 & 11,1 & - & - \\
\hline Crueldade, negligência & 10 & 1,1 & 6 & 2,6 \\
\hline Discriminação contra a pessoa idosa & 33 & 3,7 & - & - \\
\hline Induzimento a outorga de procuração & 4 & 0,5 & 1 & 0,4 \\
\hline M aus tratos & 426 & 48,5 & 109 & 47,4 \\
\hline N egativa de acolhimento & - & - & 1 & 0,4 \\
\hline Prevaricação & 1 & 0,1 & - & - \\
\hline Recusa de atendimento à saúde & 3 & 0,3 & 1 & 0,4 \\
\hline Retenção de documentos & 3 & 0,3 & 1 & 0,4 \\
\hline Perturbação do sossego & 36 & 4,1 & - & - \\
\hline Lesão Corporal & 50 & 5,7 & - & - \\
\hline Outros ${ }^{(*)}$ & 13 & 1,5 & 6 & 2,6 \\
\hline Total & 880 & 100,0 & 230 & 100,0 \\
\hline
\end{tabular}

${ }^{*}$ ) As treze denúncias incluídas na categoria Outros da D elegacia do I doso referem-sea três queixas de desaparecimento, uma de falsidade ideológica, uma comunicação falsa de crime eabuso de autoridade, uma violação de domicílio, uma queda no interior do veículo eseis registros estavam sem informação quanto ao motivo. As seis do NEAPI referem-se a um requerimento do FGTS do filho falecido, um pedido de ambulância emedicamentos, uma 1 perda decartão decrédito, um risco social, um sem condições financeiras para tratamento einternação eum sem informação. 
é que eles não têm defesas, ficam praticamente tolhidos de tomarem uma providência, de procurar a polícia, a defensoria pública, eles têm medo da coação".

E acrescentam: Ele não procura a polícia, só em último caso, com medo de quê? Da violência dos traficantes, dos donos das comunidades. Infelizmenteéo que tem que ser colocado [...] os donos das comunidades fazem o que querem. Então, eles ficam com receio, eles têm medo de procurar a polícia, procurar a justiça, atéinclusive procurar uma ajuda defora, sem ser a ajuda policial ou dejustiça, eles têm medo.

M edo também éo queimpedeo idoso de procurar por seus direitos, na visão de uma líder comunitária: Acho, que às vezes ele fica intimidado, impressionado, com receio de procurar, correr atrás daquilo. Às vezes é um ente querido dele, vai que pode acontecer alguma coisa... N ós que estamos em comunidades carentes sabemos como é o procedimento. É diferente. Ele acha que pode acontecer alguma coisa, ele quer que aquela pessoa respeite ele, mas também não quer correr atrás dos direitos dele, podevir a acontecer uma coisa pior com aque la pessoa, queele[idoso] não queira. Eleaceita aquilo ao invés de correr atrás dos direitos dele.

Como vemos na Tabela 2, a grande maioria dos idosos que sofreram algum tipo de violência édo sexo feminino ( $62 \%$ na Delegacia e $75,7 \%$ no NEAPI). A faixa etária mais acometida pelas agressões em ambas as instituições estudadas éa dos 70 aos 79 anos (31,3\% na Delegacia e 35,1\% no NEAPI).

As mulheres idosas também foram as vítimas mais freqüentes (72,5\%) na Delegacia do Idoso de Belo Horizonte ${ }^{12}$. Esse dado é corroborado pela Organização Pan-Americana de Saúde/OPAS ${ }^{14}$, que identifica a mulher como vítima mais freqüente da violência doméstica, sobretudo quando a questão de gênero se alia à maior longevidade.

A literatura nacional e internacional aponta para o fato de que os idosos mais velhos são os que apresentam maiores limitações funcionais e cognitivas e demandam maiores cuidados por parte de seus familiares. Essa necessidade de cuidados sem que o cuidador familiar esteja capacitado para lidar com essas fragilidades pode ocasionar situações de violência ${ }^{15}$.

De acordo com Souza et al. ${ }^{16}$, as relações de poder eautoridade, estabelecidas na família, ocasionadas pela codependência do binômio cuidador/idoso, constituem riscos reais e potenciais de violência intrafamiliar. Esses autores apresentam a percepção dos cuidadores em relação à razão pela qual foram escolhidos para essa função: $34 \%$ responderam que o faziam como obrigação moral; 39\% pensavam que não há outro remédio senão cuidar do idoso, para evitar a censura da família, amigos, e com isso obter a aprovação social. Desses cuidadores, $20 \%$ ainda afirmavam ser o cuidado uma carga excessiva. Apenas $2 \%$ confirmaram ser algo dignificante e 0 faziam por motivos altruístas e para manter 0 bem-estar do idoso. Isto fica claro quando se percebe que grande parte dos cuidadores são familiares também idosos, que já cuidaram de fiIhos e netos e são, por força das circunstâncias, levados a cuidar de membros em idade mais avançada, especial mente cônjuges e pais.

0 processo de cuidado de um idoso com incapacidade pode trazer desentendimentos, desavenças e também pode acarretar transtornos que exacerbam conflitos familiares gerados em épocas anteriores ou suscitar novas crises, sobretudo em famílias que enfrentam situações de pobreza e vulnerabilidade ${ }^{17}$.

Tabela 2. Distribuição proporcional das denúncias realizadas na Delegacia do I doso e no NEAPI no ano de 2004, segundo a caracterização das vítimas.

\begin{tabular}{|c|c|c|}
\hline Características das vítimas & NEAPI & DI \\
\hline \multicolumn{3}{|l|}{ Sexo } \\
\hline Feminino & 75,7 & 62,0 \\
\hline M asculino & 22,6 & 38,0 \\
\hline \multicolumn{3}{|l|}{ Faixa etária } \\
\hline 60 a 69 anos & 19,6 & 16,5 \\
\hline 70 a 79 anos & 35,1 & 31,3 \\
\hline 80 a 89 anos & 23,0 & 17,8 \\
\hline 90 e mais anos & 11,5 & 5,6 \\
\hline Sem informação & 10,8 & 28,8 \\
\hline \multicolumn{3}{|l|}{ Cor da pele } \\
\hline Brancos & - & 76,8 \\
\hline N egros e pardos & - & 23,2 \\
\hline \multicolumn{3}{|l|}{ Grau de escolaridade } \\
\hline Analfabeto & - & 5,4 \\
\hline 10 grau incompleto & - & 17,8 \\
\hline 1ํo grau completo & - & 10,7 \\
\hline $2^{0}$ grau incompleto & - & 1,8 \\
\hline 2 o grau completo & - & 33,9 \\
\hline 30 grau incompleto & - & 1,8 \\
\hline 3o grau completo & - & 28,6 \\
\hline
\end{tabular}


A informação sobre a cor da pele dos idosos apenas foi obtida na Delegacia do I doso. Pelo visto, o NEAPI não registra essa característica. É possível perceber que essa informação não é bem registrada na Delegacia, tendo em vista que em $65,8 \%$ das denúncias ( 504 casos) não consta esse dado. Entretanto, quando excluídos os sem informação, 76,8\% dos idosos são identificados como brancos e $23,2 \%$ como pretos e pardos, mas esses dados precisam ser relativizados.

Em relação à escolaridade, a informação é precária nas duas instituições aqui pesquisadas. No NEAPI, só foi possível obtêla para um caso em que a vítima possui o segundo grau completo. $\mathrm{Na}$ D elegacia do Idoso, em $92,7 \%$ dos casos ela não é informada. É importante observar que, quanto menor o grau de escolaridade, menor éo acesso a informações e isso influencia diminuindo a realização de denúncias, conforme o relato de um dos idosos entrevistados: "A gente também não sabe diretamente nem qual é o direito que a gente tem, porque nós não somos bem alfabetizados".

A Tabela 3 mostra que os autores de agressões contra os idosos distribuem-se quase que igualmente em ambos os sexos, embora as muIheres apareçam com uma freqüência um pouco maior: a mai oria é adulta e se concentra na faixa etária dos 40 aos 49 anos. Convém ressaltar que, na grande maioria dos casos, não há informação sobre a idade do agressor ( $80,2 \%$ no NEAPI e 79,4\% na Delegacia do Idoso).

Isto se explica pelo fato dea mulher ser culturalmente designada para cuidar dos mais velhos. A literatura internacional identifica al guns fatoresque determinam quais pessoas potencialmente poderão vir a ser cuidadores de idosos. São eles: parentesco, gênero, proximidadefísica eproximidade afetiva ${ }^{18}$. Portanto, ser cônjuge, do gê nero feminino, viver junto com o idoso eter uma relação conjugal ou de pais/filhos aparecem como as principais características dos quese constituem como cuidadores de pessoas idosas.

No entanto, é preciso ressaltar que o dado aqui encontrado podeestar influenciado pelo elevado percentual de casos sem informação quanto a essa variável no NEAPI $(21,4 \%$, em relação aos $2,8 \%$ da Delegacia do Idoso).

Segundo as denúncias coletadas, na maior parte das ocorrências da Delegacia do Idoso, 0 autor reside com a vítima (58,9\%), enquanto no NEAPI a situação seinverte: em $58 \%$ dos casos, 0 autor não reside com o idoso. Esse dado pode ser, em parte, explicado pelo fato de considerável parcela das queixas que chegam a esse $\mathrm{N}$ úcleo se referirem à apropriação indébita eabandono, que não necessariamente envolvem pessoas que cohabitam a mesma residência. Convém destacar queo preenchimento dessa variável éde boa qualidade na D elegacia, onde existe apenas $0,3 \%$ de casos não esclarecidos. Já no N EAPI, esse percentual sobe para 13,7.

Ainda de acordo com a Tabela 3, constatamos que a maior parte das agressões provém de familiares e de pessoas do círculo deamizades do idoso. Filhos/enteados são seus principais algozes, tanto na Delegacia do I doso (52,3\%) quanto no NEAPI $(53,4 \%)$.

Esses dados estão em concordância com a literatura nacional e internacional. Os achados nas Delegacias do Idoso de São Paulo mostram que 40\% dos agressores são filhos, netos e cônjuges. Já em $M$ inas Gerais, 45,3\% dos agressores são os filhos e em $69,63 \%$ dos casos o autor e a vítima residem no mesmo domicílio ${ }^{13}$.

Os abusos e as negligências podem acontecer por choque de geraçõ̃es, disputa por espaço físico, dificuldades financeiras ea visão estereotipada do idoso como decadentee descartável ${ }^{8}$. Apesar da maioria dos idosos brasileiros estar inserida em sua família e a Política Nacional do Idoso preconizar o incentivo aos cuidados familiares, este ambiente não tem se mostrado muito seguro para eles.

No presente estudo, esses relacionamentos conflituosos foram verbalizados por uma idosa entrevistada: M eu marido foi levado para casa da filha dele e fugiu três vezes. Disse para mim que tava sofrendo muito, que a filha deixava elepreso num quarto e falavam para ele que só podia usar aquelequarto. A casa era grande, mas ele só podia usar aquele quarto com banheiro. Eu perguntei, por que não voltava para casa? Ele me respondeu que era a família dele, não podia fazer isso. Falou que estava sofrendo muito, mas era a sua família.

A investigação mostrou que existem mecanismos de referência e contra-referência entre os órgãos de proteção ao idoso. Isso fica claro no fato de $83,8 \%$ das denúncias que chegam ao NEAPI e $46,9 \%$ das que vão para a Delegacia do Idoso serem encaminhadas pelo Ligue Idoso. Por outro lado, todo o atendimento realizado na Delegacia foi encaminhado para algum órgão estadual: $91,5 \%$ dos casos foram dirigidos ao Serviço de Investigação e Operações Policiais/SIOP, 4,5\% à Justiça Especial Criminal/JECRIM , 3,9\% à Justiça Comum e $0,1 \%$ dos atendimentos foram encaminhados à Delegacia de Defraudações.

Já no NEAPI, a maioria dos encaminhamentos foi feita para a Promotoria (45,5\%) e para o 
Tabela 3. Distribuição proporcional das denúncias realizadas na Delegacia do I doso e no NEAPI no ano de 2004, segundo a caracterização do autor da violência contra o idoso.

\begin{tabular}{|c|c|c|}
\hline Características do autor & $\begin{array}{l}\text { DI } \\
\%\end{array}$ & $\begin{array}{c}\text { NEAPI } \\
\%\end{array}$ \\
\hline \multicolumn{3}{|l|}{ Sexo } \\
\hline Feminino & 51,7 & 50,1 \\
\hline M asculino & 48,3 & 49,9 \\
\hline \multicolumn{3}{|l|}{ Faixa etária } \\
\hline 10 a 19 anos & 5,6 & 3,1 \\
\hline 20 a 29 anos & 8,3 & 14,4 \\
\hline 30 a 39 anos & 8,3 & 23,7 \\
\hline 40 a 49 anos & 38,9 & 29,4 \\
\hline 50 a 59 anos & 19,5 & 20,6 \\
\hline 60 a 69 anos & 8,3 & 5,7 \\
\hline 70 a 79 anos & 11,1 & 3,1 \\
\hline \multicolumn{3}{|l|}{ De amizade e parentesco } \\
\hline Amigo / conhecido & 18,9 & 6,7 \\
\hline (Ex) companheiro / (Ex) cônjuge & 5,4 & 3,8 \\
\hline Filho(a) / enteado(a) & 52,3 & 53,4 \\
\hline Genro / nora / cônjuge de parente & 3,4 & 3,8 \\
\hline Neto & 6,8 & 8,2 \\
\hline Outro parente & 5,5 & 13,3 \\
\hline \multicolumn{3}{|l|}{ Institucional } \\
\hline Líderes religiosos & 1,5 & 0,6 \\
\hline Funcionário de órgão público & 0,4 & - \\
\hline Funcionário de banco & 0,1 & - \\
\hline Funcionário de serviço de saúde & 1,8 & 0,6 \\
\hline $\begin{array}{l}\text { Funcionário de concessionária de } \\
\text { serviços (Light, M etrô, Rede } \\
\text { Ferroviária) }\end{array}$ & 2,8 & - \\
\hline Outro $(*)$ & 0,8 & 0,6 \\
\hline
\end{tabular}

(*) Os sete vínculos classificados como outros provenientes da delegacia do idoso são referentes a dois casos envolvendo corretores, dois com advogados, um com curadora, um com funcionário de supermercado, eum com gerente devendas; a classificada como outro do NEAPI se referea um caso envolvendo uma advogada. (**) Excluídos 93 casos da Delegacia do I doso e 24 do NEAPI sem informação.

M inistério Público (18,9\%). N otamos que 22,6\% dos casos foram arquivados após terem sido registrados pelo fato desse Núcleo não ter condições de dar andamento aos mesmos devido à falta de pessoal ou pelo fato do idoso, quando interrogado, desmentir a denúncia, por medo de incriminar um parente.

$\mathrm{N}$ a fala dos representantes das instituições de proteção ao idoso, ao responderem sobre a articulação das instituições para a garantia dos direi- tos dos idosos, verificamos a grande carência de órgãos e recursos para um funcionamento adequado da rede de proteção. Esse ano até que não houve tanta articulação, mas uns anos anteriores nós tínhamos bastante intercâmbio com o M inistério Público ecom a própria delegacia do idoso. No intercâmbio com o ministério, a gente tava sempre conversando. A cada mudança de gestão do M inistério Público começa tudo de novo, isso demora um pouco. M astemosintercâmbio com a delegacia, com o consel ho do idoso, que solicita bastante.

Suas fal as demonstram que esses órgãos não estão preparados para receber a demanda deidosos vítimas de violência e que as esferas de poder (estado e município) não atribuem a devida importância às questões de proteção ao idoso.

\section{Consideraçõesfinais}

A análise dos dados aqui mostrada aponta para algumas questões que merecem ser destacadas. Primeiramente, verificamos que a principal negação dos direitos do idoso aparece na forma da violência que se abate sobre eles. Os maus tratos sofridos no ambiente doméstico se destacam corroborando uma série de outros estudos ${ }^{19,20}$. Daí a importância de se realizar atuações junto à família que, em geral, é a instituição responsável pelo cuidado do idoso, inclusive com os aparatos legais como a Constituição, a Política Nacional do Idoso, a Política Nacional de Saúde do Idoso e o Estatuto do Idoso, no sentido de instrumentalizá-la para o exercício desse cuidado. Reforçar os vínculos e a rede familiar para que ela possa atuar como instituição protetora, em vez de algoz, parece ser uma estratégia política extremamentenecessária.

A afirmação acima é reforçada pelo fato de os idosos com idade mais avançada, que constituem um grupo com maior fragilidade funcional ecognitiva, terem representado considerável parcela daqueles que foram atendidos nas duas instituições aqui investigadas. São justamente esses os que mais necessitam da segurança e do apoio que a rede familiar poderia proporcionar. No entanto, essa maior carência, muitas vezes, gera relacionamentos violentos por parte dos cuidadores familiares, conforme os dados demonstraram. Esta violência contra o idoso frágil cometida por membros da família ou acompanhantes bem conhecidos da vítima tem sido objeto de preocupação da Organização Pan-Americana de Saúde ${ }^{13}$ e deveria ser alvo de ações nos âmbitos estadual e municipal do Rio de Janeiro. 
Os dados aqui analisados também deixam claraa existência dealgumas deficiências: 1) variáveis sem informação, sem o registro de características básicas das vítimas e dos agressores; 2 ) a quantidade ea capacitação dos funcionários têm gerado arquivamento de processos sem solução, morosidade no andamento dos casos e atendimento inadequado às necessidades do idoso; e 3) há carências em termos de quantidade de instituições, pois existeuma só delegacia especializada de atendimento ao idoso para todo o estado.

Essas limitações redundam em sérios prejuízos, pois os casos deixam de ser notificados; os registros ora não são realizados, ora o são duplamente; os processos levam longo tempo para serem solucionados ou sequer o são. A pouca agilidade do sistema, causada pelas idas e vindas do processo entre distintas instituições, para esclarecimentos das dúvidas, leva a população a perceber o inquérito policial como uma forma de burocratização da justiça. Tudo isso, em última instância, significa que entreo direito constituído e a garantia do direito do idoso ainda há um longo caminho a ser percorrido, como bem demonstra a fala de um idoso. "Você quer procurar um direito, como você vai buscar se você não tem quem te dêapoio?Vai procurar o quê? A defensoria pública? A justiça gratuita aqui no Brasil, no meu entender, é anedota".

Para o representante da Delegacia do Idoso, além da precariedade de pessoal e de delegacias especializadas, pois existe apenas "uma delegacia pra atender a toda a população, deveria ter outras del egacias e não têm", o estado carece de um centro apolítico quefiltreeconcentretodas as denúncias em relação ao idoso. Seria necessário quehouvesse um banco de dados único, que contivesse um histórico com todos os casos de violência por ele sofridos, desde a abertura do primeiro processo. Esse sistema facilitaria a identificação de idosos mais vulneráveis a situações de violência, na medida em quepoderia captar os casos reincidentes, permitindo maior controleefacilidadena fiscalização por parte do M inistério Público.

Esses parecem ser problemas que dificultam 0 adequado desenvolvimento das ações institucionais e atuam na contramão da garantia dos direitos da pessoa idosa, pois geram subregistro e desconhecimento sobre a real situação de desrespeito aos direitos dos idosos.

Concluímos afirmando que o fluxo institucional de captação, registro, atendimento eencaminhamento dos casos de desrespeito eviolência contra o idoso no Rio de Janeiro ainda carece de articulação, integração eagilidade, o que poderia resultar no aumento de sua eficiência, expresso, sobretudo, na maior resolutividade dos casos.

No caso específico da realidade da comunidade estudada, várias experiências de movimentos e instituições locais em defesa dos direitos de seus moradores foram vilmente boicotadas e esfaceladas pelo tráfico. Isso tem seconstituído um importante fator impeditivo do fortalecimento das redes informais locais, do mesmo modo que dificulta a entrada das instituições formais na comunidade. Por outro lado, esses órgãos formais, por estarem submetidos às injunções político-partidárias têm, historicamente, desenvolvido políticas descontínuas que acabam caindo no descrédito da população local edificultando a ação efetiva que poderiam realizar.

Diante dos dados e do contexto de violência a que estão submetidos os idosos e a população em geral, moradores de áreas como a aqui estudada, fica clara a necessidade premente do fortalecimento de redes formais e informais de apoio e proteção, no sentido de resgatar sentimentos de identidade comum, de pertencimento à comunidade e de coletividade. Enfim, a formação de redes de solidariedade como um caminho para o resgate da cidadania e o enfrentamento da violência.

\section{Colaboradores}

ER de Souza participou da concepção, análise e escrita; AP Ribeiro, S Atie eAC de Souza participaram da análise e escrita; CC M arques auxiliou nos recortes dos dados incluídos no artigo. 


\section{Agradecimentos}

À D el egacia do I doso eao NEAPI por terem gentilmente aberto suas portas para a realização do levantamento dos dados. À FAPERJ pelo apoio dado à pesquisa. Aos sujeitos participantes que dedicaram parte do seu precioso tempo em prol de uma pesquisa.

\section{Referências}

1. Camarano AA. Mulher idosa: suporte familiar ou agente de mudança. Estudos Avançados 2003; 17(49):35-63.

2. M inayo MCS, Souza ER. Violência contra idosos: é possível prevenir. In: Souza ER, M inayo MCS, organizadoras. Impacto da violência na saúde dos brasileiros. Brasília: M inistério da Saúde; 2005. p.141-165.

3. Sluzki C. A rede social na prática sistêmica: alternativas terapêuticas. São Paulo: Casa do Psicólogo; 1997.

4. Erbolat RM PL. Relações Sociais na Velhice. In: Freitas EV, Py L, Cançado FAX, Gorzoni M L, organizadores. Tratado de geriatria e gerontologia. Rio de Janeiro: Guanabara Koogan; 2002.

5. Domingues M ARC. M apa mínimo de relações: adaptação de um instrumento gráfico para configuração da rede de suporte social do idoso [dissertação]. São Paulo (SP): Faculdade de Saúde Pública, Universidade de São Paulo; 2000.

6. Valla VV, Stotz EN. Educação, saúde e cidadania. Rio de Janeiro: Vozes; 1994.

7. Griep RH, Chor D, Faerstein E, Lopes C. Apoio social: confiabilidade testereteste de escala no Estudo Pró-Saúde. Cad Saúde Pública 2003; 19(2):625-634.

8. Lemos N, M edeiros SL. Suporte social ao idoso dependente. In: Freitas EV, Cançado FAX, Gorzoni $M L$, organizadores. Tratado de geriatria e gerontologia. Rio de Janeiro: Guanabara Koogan; 2002.

9. Souza ER, Ribeiro AP, Atie S, Souza A. 0 estado de direito e a violência contra o idoso. Rio de Janeiro: CLAVES/ENSP/Fiocruz; 2006.

10. Gênesis. Relatório de conclusão dos trabalhos realizados pelo Curso de Capacitação de Agentes Sociais para atuar junto a idosos em situação de risco de violência. Brasília: Subsecretaria de Promoção e Defesa dos Direitos Humanos do M inistério da Justiça; 2003.

11. M inayo M CS. 0 desafio do conhecimento: pesquisa qualitativa em saúde. São Paulo: Hucitec/Abrasco; 2004.
12. Saad SM. Tendências e conseqüências do envelhecimento populacional no Brasil. In: Fundação Sistema Estadual de Análise de Dados - SEAD, organizadora. A população idosa e o apoio familiar. São Paulo: Fundação SEAD; 1991. [Série Informe Demográfico]

13. Minayo MCS. Violência contra idosos: 0 avesso e 0 respeito à experiência e à sabedoria. Braślia: Secretaria Especial dos Direitos Humanos; 2004.

14. Organização Pan-Americana de Saúde. Envelhecimento ativo: uma política de saúde. Brasília: OPAS; 2005.

15. Gonçalves SRS. (In)visibilidade da violência simbólica no cotidiano do cuidador familiar do idoso portador de Alzheimer [dissertação]. Fortaleza (CE): Universidade de Fortaleza; 2005.

16. Souza AS, M eira EC, N éri IG, Silva JA, Gonçalves LHT. Fatores de risco e maus-tratos ao idoso na relação idoso/cuidador em convivência intrafamiliar. Textos Envelhecimento [periódico na Internet]. 2004; 7(2). Disponível em: http://www.unati.uerj.br/ tse/scielo.php?script $=$ sci_arttext $\&$ pid $=S 1517$ $59282004000200005 \&$ Ing=pt\&nrm=iso

17. Torres SVS, Sé EVG, Queroz NC. Fragilidade, dependência e cuidado: desafios ao bem-estar dos idosos e de suas famílias. In: Diogo MJD, Neri AL, Cachioni M, organizadores. Saúde e qualidade de vida na velhice. Campinas: Alínea; 2004.

18. Karsch UM . Idosos dependentes: famílias e cuidadores. Cad Saúde Pública 2003; 19(3):861-866.

19. M inayo M CS. Violência contra idosos: relevância para um velho problema. Cad Saúde Pública 2003; 19(3):783-791.

20. M inayo MCS, Souza ER. As múltiplas mensagens da violência contra idosos. In: Souza ER, M inayo M CS, organizadoras. Violência sob o olhar da saúde: a infrapolítica da contemporaneidade brasileira. Rio de Janeiro: Fiocruz; 2003.

Artigo apresentado em 09/04/2007

A provado em 05/06/2007 